\title{
Safety of Sedated Therapeutic Endoscopic Retrograde Cholangiopancreatography in Patients Older than 70 Years Old
}

\author{
Su Jung Baik, Sun Young $\mathrm{Yi}^{1}$, Hye-Kyung Jung ${ }^{1}$, Seong-Eun Kim ${ }^{1}$ \\ Department of Gastroenterology, Health Promotion Unit, Yonsei University Gangnam Severance Hospital, ${ }^{1}$ Department of Internal \\ Medicine, Ewha Medical Research Institutes, Ewha Womans University School of Medicine, Seoul, Korea
}

\begin{abstract}
Objectives: The purpose of this study was to compare the safety and efficacy of midazolam sedated Endoscopic retrograde cholangiopancreatography (ERCP) with unsedated ERCP in patients 70 years of ages and older.

Methods: Seventy elderly patients 70 years of age or older who underwent ERCP were divided into two groups: midazolam sedated group $(n=43)$ and unsedated group $(\mathrm{n}=27)$. Procedure time, success rate, complications related with ERCP procedure, satisfaction score were analyzed between two groups.

Results: Mean procedure time was 20.6 minutes for sedated group and 21.0 minutes for unsedated group $(\mathrm{P}=0.88)$. Success rate was $87.5 \%$ for sedated group and $100 \%$ for unsedated group $(\mathrm{P}=0.07)$. Incidence of complications from ERCP procedure showed no significant differences between the sedated and unsedated groups $(\mathrm{P}=0.10)$. There was no mortality in both groups related to the sedation or post-ERCP complication. Compared to the unsedated procedure, the sedated ERCP procedure was associated with higher patient satisfaction $(\mathrm{P}<0.001)$ and better repeat compliance $(\mathrm{P}=0.004)$.

Conclusion: There was no significant difference in success rate and complications at sedated and unsedated ERCP in patients 70 years of age and older. Unsedated ERCP showed 66.6\% satisfaction score compared to sedated ERCP. (Ewha Med J 2014;37(2):92-97)
\end{abstract}

\author{
Received October 11, 2013 \\ Accepted July 7, 2014 \\ Corresponding author \\ Sun Young Yi \\ Department of Internal Medicine, \\ Ewha Womans University School of Medicine, \\ 1071 Anyangcheon-ro, Yangcheon-gu, \\ Seoul 158-710, Korea \\ Tel: 82-2-2650-5575, Fax: 82-2-2655-2075 \\ E-mail: syy@ewha.ac.kr
}

Key Words

Elderly; Endoscopic retrograde

cholangiopancreatography; Conscions

sedation

\section{Introduction}

The therapeutic procedure of endoscopic retrograde cholangiopancreatography (ERCP) of pancreaticobiliary disease is safe and effective [1]. Biliary and pancreatic diseases are frequently associated with complications in the elderly and are therefore attracting more attention owing to the increasing elderly population [2,3]. Several studies have been conducted on the safety and efficacy of therapeutic ERCP for elderly patients [4-6]. However, there is concern about the risk of cardiopulmonary complications and mortality in elderly patients who undergo ERCP, especially when they are sedated during the procedure $[7,8]$. Studies on the safety and efficacy of sedative ERCP in elderly patients have predominantly been conducted in Western populations $[9,10]$. Only a few prospective studies have been reported on elderly Asian patients [6,7]. The aim of our study was to evaluate the safety and efficacy of midazolam induced sedative ERCP in elderly patients and also conducted small study of unsedated ERCP in elderly. Seventy patients were enrolled and therapeutic ERCP was performed with or without sedation.

\section{Methods}

\section{Subjects}

Seventy patients older than 70 years were enrolled and divided into two groups. A single blind randomized allocation was 
employed. The allocation sequence was concealed, and patients were assigned allocation on the day of ERCP procedure. ERCP procedures were performed by an experienced endoscopist at the Ewha Womans University Mokdong Hospital, Seoul, Korea. Written informed consent was obtained from each patient. $\mathrm{Pa}-$ tients who refused the allocation were excluded from the study. All date from the study were stored on an encrypted server, and passwords were required to log in.

Overall, 70 patients were enrolled the study. Forty-three patients were allocated to midazolam induced sedated ERCP group, and 27 patients were allocated to unsedated ERCP group.

We analyzed underlying diseases and past medical history, including pancreatitis, previous cholecystectomy, and medications such as antiplatelet agents. ERCP findings, success rate, procedure duration, adverse events during ERCP (hypoxemia, electrocardiogram change, and hypotension), procedure-related complications (pancreatitis, bleeding, and perforation), and mortality within 1 month were evaluated.

\section{ERCP procedure and monitoring}

The subjects fasted for at least 8 hours before the ERCP. A standard ERCP was performed with the subjects in the lateral decubitus position, using an Olympus side-viewing video duodenoscope (Olympus TGF240; Olympus Optical Co, Tokyo, Japan). The patients were sedated by intravenous administration of $0.06 \mathrm{mg} / \mathrm{kg}$ of midazolam (Dormicum; Roche Korea, Seoul, Korea) before the procedure. To reduce duodenal motility and secretion, $10 \mathrm{mg}$ of cimetropium bromide was administered intravenously. For pain control, $50 \mathrm{mg}$ of meperidine was administered intramuscularly before the procedure. Monitoring included continuous assessment of peripheral oxygen saturation $\left(\mathrm{SpO}_{2}\right)$, heart rate, and blood pressure. Continuous oxygen administration was not used during sedation. When the $\mathrm{SpO}_{2}$ was less than 90\%, oxygen was provided and an antidote for midazolam, flumazenil (Anexate; Roche Korea) was injected.

Hypoxemia was defined as a $\mathrm{SpO}_{2}$ level of less than $90 \%$ for at least 10 seconds. Troponin $\mathrm{T}(\mathrm{TnT}$ ) elevation was defined as an increase in TnT level of at least $0.01 \mathrm{ng} / \mathrm{mL}$. An electrocardiogram (ECG) change was defined as a new downward slope or horizontal elevation of the ST segment, an ECG decrease of $0.1 \mathrm{mV}$ or more, or an ST segment elevation of $0.2 \mathrm{mV}$ or more above baseline for at least 1 minute. Tachycardia was defined as heart rate in excess of 100 beats per minute (bpm), bradycardia as heart rate of less than $50 \mathrm{bpm}$, and hypertension as systemic blood pressure greater than $200 \mathrm{mmHg}$. Hypotension was defined as systemic blood pressure less than 80 mmHg. Post-ERCP pancreatitis was defined as significant persistent ( $\geq 24$ hours) abdominal pain associated with an elevation in amylase or lipase by at least 3 times above the upper limit of normal. After the procedure, vital signs and laboratory findings, including TnT levels, were noted. Morbidity and mortality were recorded for 30 days after the ERCP procedure.

\section{Satisfaction score}

A 10-point visual analogue scale was used to estimate the tolerance and satisfaction levels of patients on the day after the procedure. A score of 0 indicated a very poor satisfaction level, and a score of 10 indicated a very high one. Compliance with the procedure was assessed according to whether the patient would agree to a repetition of the same procedure, should the need arise.

\section{Statistical analysis}

The SAS ver. 9.1 (SAS Institute Inc., Cary, NC, USA) was used for statistical analysis. Data are expressed as the mean and standard deviation. Statistical analysis was performed using the Student $t$ test. Logistic regression analysis was performed between complication and sedation and between complication and procedure time over 30 minutes. A two-tailed $\mathrm{P}$ value $<0.05$ was considered statistically significant.

\section{Results}

\section{General characteristics and clinical presentations}

The demographic and clinical characteristics of subjects in the two study groups were compared. There were no statistically significant differences in age, sex, weight, height, or smoking habits between two groups (Table 1).

The difference in the incidence of comorbid disease between groups was not significant. The most common comorbidity was hypertension, followed by diabetes mellitus, pulmonary diseases (such as asthma and chronic obstructive pulmonary disease), and cardiovascular diseases (such as coronary artery disease and congestive heart failure). There were no significant differences between previous history of pancreatitis, cholecystectomy, or medication between groups. 
Table 1. Demographic and clinical data of study participants who underwent ERCP under sedation or without sedation

\begin{tabular}{|c|c|c|c|}
\hline Variable & $\begin{array}{c}\text { Sedated } \\
\text { group }(n=43)\end{array}$ & $\begin{array}{c}\text { Unsedated } \\
\text { group }(n=27)\end{array}$ & $\begin{array}{c}\text { Difference } \\
\text { (P value) }\end{array}$ \\
\hline Gender (male:female) & $20: 23$ & $12: 15$ & 0.87 \\
\hline Mean age (yr) & $77.5 \pm 5.0$ & $77.4 \pm 4.8$ & 0.99 \\
\hline Mean weight (kg) & $54.8 \pm 7.6$ & $57.6 \pm 10.3$ & 0.19 \\
\hline $\begin{array}{l}\text { Smoking status } \\
\text { Current smoking } \\
\text { Smoked in past } \\
\text { Never smoked }\end{array}$ & $\begin{array}{r}2 \\
14 \\
27\end{array}$ & $\begin{array}{r}0 \\
6 \\
21\end{array}$ & 0.63 \\
\hline Hypertension & 23 & 14 & 0.90 \\
\hline Diabetes mellitus & 9 & 8 & 0.43 \\
\hline Chronic renal disease & 3 & 1 & 0.55 \\
\hline Pulmonary disease & 7 & 4 & 0.87 \\
\hline Cardiovascular disease & 8 & 2 & 0.16 \\
\hline Cerebral vascular accident & 2 & 4 & 0.19 \\
\hline Previous pancreatitis & 1 & 2 & 0.37 \\
\hline Previous ERCP & 4 & 0 & 0.11 \\
\hline Cholecystectomy & 11 & 5 & 0.49 \\
\hline Antiplatelet agent & 15 & 6 & 0.25 \\
\hline
\end{tabular}

ERCP, endoscopic retrograde cholangiopancreatography.

Table 2. Comparison between indications for ERCP in sedated groupand unsedated group $(\mathrm{P}=0.87)$

\begin{tabular}{lcc}
\hline \multicolumn{1}{c}{ Variable } & $\begin{array}{c}\text { Sedated } \\
\text { group (\%) }\end{array}$ & $\begin{array}{c}\text { Unsedated } \\
\text { group (\%) }\end{array}$ \\
\hline Choledocholithiasis & $34(79.1)$ & $22(81.5)$ \\
Bile duct stenosis & $1(2.3)$ & $1(3.7)$ \\
Papillary tumor of pancreas & $5(11.6)$ & $2(7.4)$ \\
AUPBD & $3(7.0)$ & $2(7.4)$ \\
\hline
\end{tabular}

$E R C P$, endoscopic retrograde cholangiopancreatography; AUPBD, anomalous union of pancreaticobiliary duct.

The most common clinical presentation at admission in both groups was right upper-quadrant pain. The most common indication for ERCP was choledocholithiasis in both groups (Table 2).

\section{ERCP results}

The mean dosage of midazolam used for sedation in sedated group was $3.5 \pm 0.8 \mathrm{mg}$. The duration of the ERCP procedure ranged from 5 to 67 minutes, and the mean duration of the procedure did not differ between groups (20.6 \pm 9.3 minutes vs.
Table 3. Comparison between ERCP results of sedated group and unsedated group

\begin{tabular}{lccc}
\hline \multicolumn{1}{c}{ Variable } & $\begin{array}{c}\text { Sedated } \\
\text { group (\%) }\end{array}$ & $\begin{array}{c}\text { Unsedated } \\
\text { group (\%) }\end{array}$ & $\begin{array}{c}\text { Difference } \\
\text { (P value) }\end{array}$ \\
\hline Success rate & $38(88.4)$ & $27(100)$ & 0.07 \\
${\text { ERCP time }(\min )^{*}}^{*}$ & $20.6 \pm 9.3$ & $21.0 \pm 11.7$ & 0.88 \\
ERCP results & $38(88.4)$ & $22(81.5)$ & 0.87 \\
CBD stone & $2(4.6)$ & $4(14.8)$ & \\
Bile duct dilation $^{\dagger}$ & $1(2.3)$ & 0 & \\
Biliary malignancy $^{*}$ & $2(4.7)$ & $1(3.7)$ & \\
IPMN & $22(51.2)$ & $17(63.0)$ & 0.34 \\
Diverticulum & $32(74.4)$ & $25(92.6)$ & 0.06 \\
\hline EST &
\end{tabular}

ERCP, endoscopic retrograde cholangiopancreatography; $C B D$, common bile duct; IPMN, intraductal papillary mucinous neoplasm; EST, endoscopic sphincterotomy.

${ }^{*}$ ERCP time expressed as mean \pm SD values. ${ }^{\dagger}$ Bile duct dilation without apparent cause.

21.1 \pm 11.7 minutes; $\mathrm{P}=0.88$ ) (Table 3 ). The success rate was $88.4 \%$ for sedated group and $100 \%$ for unsedated group, but this difference was not significant $(\mathrm{P}=0.07)$. Failure was seen on three patients with cannulation failure due to large diverticulum, two patients with clearance failure due to multiple and large stones. The most common ERCP finding in both groups was a common bile duct stones ( $88.4 \%$ vs. $81.5 \%$ ).

\section{ERCP complications}

There were no significant cardiopulmonary events, including ECG changes, hypoxemia, and hypotension in both groups during the ERCP procedure $(\mathrm{P}=0.62)$ (Table 4).

No significant differences between number of complications that occurred after ERCP were seen $(\mathrm{P}=0.10)$. These consisted of 4 cases of transient pancreatitis, 2 cases of perforation and 1 case of bleeding in sedated group, and 1 case of pancreatitis after ERCP in unsedated group.

Two cases of perforation were seen; 70 year-old male patient after ampullectomy of ampulla of vater adenoma with severe dysplasia and 87 year-old male patient after removal fail of impacted CBD stone. ERCP time of two cases of perforation were 38 minutes and 30 minutes, respectively. One case of bleeding was seen in 76 year-old male patient after advanced EST for removal of CBD stone. In bleeding case, ERCP time was 15 minutes.

Minor complications consisted of ECG changes without TnT 
Table 4. Comparison between the number of complications in sedated group and unsedated group

\begin{tabular}{lccc}
\hline Variable & $\begin{array}{c}\text { Sedate } \\
\text { group (\%) }\end{array}$ & $\begin{array}{c}\text { Unsedated } \\
\text { group (\%) }\end{array}$ & $\begin{array}{c}\text { Difference } \\
\text { (P value) }\end{array}$ \\
\hline $\begin{array}{c}\text { During ERCP } \\
\text { Hypoxemia }\end{array}$ & $2(4.7)$ & 0 & 0.62 \\
ECG change & $1(2.3)$ & $1(3.7)$ & \\
Hypotension & 0 & $1(3.7)$ & \\
No complication & $40(93.0)$ & $25(92.6)$ & \\
After ERCP & & & 0.10 \\
Pancreatitis & $4(9.3)$ & $1(3.7)$ & \\
Bleeding & $1(2.3)$ & 0 & \\
Perforation & $2(4.7)$ & 0 & \\
No complication & $36(88.7)$ & $26(96.3)$ & \\
\hline
\end{tabular}

ERCP, endoscopic retrograde cholangiopancreatography; ECG, electrocardiogram.

Table 5. Comparison between participant satisfaction level by visual analogue score and compliance of sedated group and unsedated group

\begin{tabular}{cccc}
\hline Variable & $\begin{array}{c}\text { Sedated } \\
\text { group }\end{array}$ & $\begin{array}{c}\text { Unsedated } \\
\text { group }\end{array}$ & $\begin{array}{c}\text { Difference } \\
\text { (P value) }\end{array}$ \\
\hline Satisfaction score* $^{*}$ & $7.9 \pm 1.8$ & $5.6 \pm 2.7$ & $<0.001$ \\
Repeat compliance (\%) & 90.7 & 63.0 & 0.004 \\
\hline
\end{tabular}

*Score on a scale of 1 to 10 points (1, very poor satisfaction; 10, very high satisfaction). mean $\pm S D$

elevation in 3 patients and transient pleural effusions in $2 \mathrm{pa}^{-}$ tients. There were 2 cases of TnT level elevation without ECG change (1 for sedated group, 1 for unsedated group) and there were no significant differences between two groups $(\mathrm{P}=0.65)$. Minor complications were clinically insignificant. No mortalities occurred within a month of the procedure in both groups. The logistic regression analysis showed no significance between complication and sedation $(\mathrm{P}=0.14)$ and between complication and procedure time over 30 minutes $(\mathrm{P}=0.78)$.

\section{Satisfaction score}

The satisfaction score was greater in sedated group than unsedated group $(7.9 \pm 1.8$ vs. $5.6 \pm 2.8 ; \mathrm{P}<0.001)$, as was the compliance for a repeat procedure $(90.7 \%$ vs. $63.0 \%$; $\mathrm{P}=0.004$ ) (Table 5). Unsedated ERCP showed relatively $66.6 \%$ satisfaction score if sedated ERCP satisfaction score was $100 \%$.

\section{Discussion}

ERCP is an effective endoscopic procedure for the treatment of biliary and pancreatic diseases [1]. There is concern about using ERCP for elderly patients because of possible cardiopulmonary complications [11]. Despite this concern, the demand for ERCP in elderly patients is increasing because of the increasing incidence of biliary tract disease $[2,11]$. As the population ages, the use of therapeutic endoscopic procedures for treatment of the elderly will increase [2,12]. Even when biliary drainage is successful in elderly patients, they still exhibit a high incidence of severe cholangitis and additional medical complications (such as hypotension, altered sensorium, and renal failure), and the mortality rate is $9.6 \%$ [13]. Transient myocardial ischemia and various cardiac arrhythmias frequently occur in elderly patients during ERCP $[14,15]$.

Sedation is a critical issue for elderly patients. Most studies on sedation have compared its effects in elderly and younger patients by using retrospective experimental designs [3,11]. Few prospective studies have been performed to examine the risk of sedation in the elderly in terms of their tolerance of ERCP procedures [16-18]. Sedation regimens for ERCP are midazolam alone or midazolam plus opioids, propofol alone or balanced propofol sedation (propofol in combination with midazolam and meperidine) [19]. The midazolam sedation used had been previously shown to result in a good level of satisfaction, few paradoxical responses, and a short discharge time without any side effects [20].

Arterial hypoxemia, arrhythmias, and myocardial ischemia have been associated with ERCP in elderly patients [10,11]. Patients undergoing ERCP may develop true myocardial ischemia with reduced myocardial blood flow [18]. Elevated cardiospecific troponin levels have been presented as biochemical evidence of ERCP-related myocardial injury [11]. Troponin levels in patients over 65 years of age become elevated if the duration of ERCP exceeds 30 minutes [11]. In the present study, the mean procedure time was approximately 20 minutes, and the TnT level after ERCP did not differ significantly in both sedated and unsedated groups. And the linear regression analysis showed no significance between major complication and procedure time over 30 minutes. Changes in ECG and TnT levels after ERCP in this study were transient and not clinically significant.

Elderly patients who undergo ERCP may be at risk of cardio- 
pulmonary complications because of preexisting cardiovascular disease, combinations of benzodiazepine and opioid sedation, or prolonged procedures [11,21]. Several studies have recently been conducted on ERCP in elderly Asian patients. Sugiyama et al. [22] showed that ERCP and sphincterotomy are safe treatments for choledocholithiasis in people aged above 90 years. Between $2 \%$ and $9 \%$ of elderly patients require ventilatory support after endoscopic sphincterotomy for bile duct stones [22]. The most common complications of ERCP in elderly Asian patients were cholangitis, pancreatitis, and biliary perforation [22]. The complication rate associated with therapeutic ERCP in elderly patients was $2.6 \%$ according to a prospective study, and shortterm complications after endoscopic sphincterotomy were not related to age [23].

Of the previously reported prospective studies, only 3 addressed sedation and age [16-18,20]. Moreover, most prospective studies were conducted on Western patients. The prospective studies for Asian patients concerned propofol sedation [6,7] or endoscopic sphincterotomy for elderly patients [23].

In the present study, in addition to a higher satisfaction score in the sedated group $(\mathrm{P}<0.001)$, procedure tolerance or repeat compliance was also higher in the sedated group $(\mathrm{P}=0.004)$. The complications were not significant in both groups, and there was no mortality in this study. A limitation of our study is the restricted study population, which may be responsible for the differences in certain observations of this study compared to those of other studies. For instance, there was a relatively low incidence of malignancies and mortality in our subject population.

In conclusion, sedated ERCP is a safe and effective procedure for elderly patients aged 70 years and above. Moreover, patients who underwent sedated ERCP were more satisfied and had better compliance than those treated with nonsedative ERCP.

\section{Acknowledgments}

This study was awarded a travel grant by the United European Gastroenterology Federation (UEGF) Scientific Committee for presentation at the 2008 United European Gastroenterology Week (UEGW) in Vienna, Austria.

\section{References}

1. Mitchell RM, O'Connor F, Dickey W. Endoscopic retrograde cholangiopancreatography is safe and effective in patients 90 years of age and older. J Clin Gastroenterol 2003;36:72-74.

2. Ross SO, Forsmark CE. Pancreatic and biliary disorders in the elderly. Gastroenterol Clin North Am 2001;30:531-545.

3. Katsinelos P, Paroutoglous G, Kountouras J, Zavos C, Beltsis A, Tzovaras G. Efficacy and safety of therapeutic ERCP in patients 90 years of age and older. Gastrointest Endosc 2006;63:417-423.

4. Ashton CE, McNabb WR, Wilkinson ML, Lewis RR. Endoscopic retrograde cholangiopancreatography in elderly patients. Age Ageing 1998;27:683-688.

5. Chong VH, Yim HB, Lim CC. Endoscopic retrograde cholangiopancreatography in the elderly: outcomes, safety and complications. Singapore Med J 2005;46:621-626.

6. Horiuchi A, Nakayama Y, Tanaka N, Ichise Y, Katsuyama Y, Ohmori S. Propofol sedation for endoscopic procedures in patients 90 years of age and older. Digestion 2008;78:20-23.

7. Ong WC, Santosh D, Lakhtakia S, Reddy DN. A randomized controlled trial on use of propofol alone versus propofol with midazolam, ketamine, and pentazocine "sedato-analgesic cocktail" for sedation during ERCP. Endoscopy 2007;39:807-812.

8. Rodriguez-Gonzalez FJ, Naranjo-Rodriguez A, Mata-Tapia I, Chicano-Gallardo M, Puente-Gutierrez JJ, Lopez-Vallejos P, et al. ERCP in patients 90 years of age and older. Gastrointest Endosc 2003;58:220-225.

9. Schilling D, Rosenbaum A, Schweizer S, Richter H, Rumstadt B. Sedation with propofol for interventional endoscopy by trained nurses in high-risk octogenarians: a prospective, randomized, controlled study. Endoscopy 2009;41:295-298.

10. Paspatis GA, Manolaraki MM, Vardas E, Theodoropoulou A, Chlouverakis G. Deep sedation for endoscopic retrograde cholangiopancreatography: intravenous propofol alone versus intravenous propofol with oral midazolam premedication. Endoscopy 2008;40:308-313.

11. Fisher L, Fisher A, Thomson A. Cardiopulmonary complications of ERCP in older patients. Gastrointest Endosc 2006;63:948-955.

12. Rastogi A, Campbell DR. ERCP in the elderly: how safe is it? (marathons, marathon ERCPs, and marathon ERCPs in the elderly). Gastrointest Endosc 2006;63:956-958.

13. Agarwal N, Sharma BC, Sarin SK. Endoscopic management of acute cholangitis in elderly patients. World J Gastroenterol 2006;12:6551-6555.

14. Kounis NG, Zavras GM, Papadaki PJ, Kouni SN, Batsolaki M, Gouvelou-Deligianni GV, et al. Electrocardiographic changes in elderly patients during endoscopic retrograde cholangiopancreatography. Can J Gastroenterol 2003;17:539-544.

15. Christensen M, Hendel HW, Rasmussen V, Hojgaard L, Schulze S, Rosenberg J. Endoscopic retrograde cholangiopancreatography causes reduced myocardial blood flow. Endoscopy 2002;34:797-800.

16. Clarke GA, Jacobson BC, Hammett RJ, Carr-Locke DL. The indications, utilization and safety of gastrointestinal endoscopy in an extremely elderly patient cohort. Endoscopy 2001;33:580-584.

17. MacMahon M, Walsh TN, Brennan P, Osborne H, Courtney MG. 
Endoscopic retrograde cholangiopancreatography in the elderly: a single unit audit. Gerontology 1993;39:28-32.

18. Koklu S, Parlak E, Y?ksel O, Sahin B. Endoscopic retrograde cholangiopancreatography in the elderly: a prospective and comparative study. Age Ageing 2005;34:572-577.

19. Moon SH. Sedation regimens for gastrointestinal endoscopy. Clin Endosc 2014;47:135-140.

20. Yi SY, Shin JE. Midazolam for patients undergoing upper gastrointestinal endoscopy: a prospective, single-blind and randomized study to determine the appropriate amount and time of initiation of endoscopy. J Gastroenterol Hepatol 2005;20:1873-
1879.

21. Christensen M, Matzen P, Schulze S, Rosenberg J. Complications of ERCP: a prospective study. Gastrointest Endosc 2004;60:721731.

22. Sugiyama M, Atomi Y. Endoscopic sphincterotomy for bile duct stones in patients 90 years of age and older. Gastrointest Endosc 2000;52:187-191.

23. Hui CK, Liu CL, Lai KC, Chan SC, Hu WH, Wong WM, et al. Outcome of emergency ERCP for acute cholangitis in patients 90 years of age and older. Aliment Pharmacol Ther 2004;19:11531158. 